\title{
Plasma Cold Hearth Remelting of UDIMET@ Alloy 718
}

\author{
E. Samuelsson, G. E. Maurer \\ Special Metals Corporation \\ New Hartford, NY \\ M. E. Schlienger, R. E. Haun \\ Retech, Inc. \\ Ukiah, CA \\ J. S. Krafcik \\ Sandia National Laboratories \\ Livermore, $\mathrm{CA}$
}

\begin{abstract}
Cold hearth remelting (CHR) is receiving increased attention because of its ability to remove high and low density inclusions from titanium-based alloys. To better understand this melt technology, plasma cold hearth remelting (PCHR) of a superalloy has been investigated to evaluate if melting and casting parameters can be adequately controlled to produce acceptable ingot structure, cleanliness and overall chemistry. UDIMET A Aloy 718 (U718) was chosen for this study because of its widespread use in the aerospace industry and its sensitivity to chemical segregation.

Electrodes were remelted from $190 \mathrm{~mm}$ diameter to $203 \mathrm{~mm}$ diameter ingots. A statistical experimental $2^{3-1}$ design was applied to the variables: mold torch power, mold electromagnetic (EM) stirring and hearth slag control gas jets. The effects of these variables were assessed by macro- and micro-structure, ingot surface, chemical profiles, and electron beam button cleanliness testing (EBBT). The characteristics of the PCHR material were compared to those of a $203 \mathrm{~mm}$ diameter vacuum arc remelted (VAR) U718 ingot and to triple-melt [vacuum induction melted-electroslag remelted-vacuum arc remelted (VIM-ESRVAR) ] U718 material.

The data indicate that PCHR improves the cleanliness of the input material by an order of magnitude, resulting in oxide cleanliness ratings similar to those of triple-melt U718. Asymmetrical pool profiles and associated tree-ring patterns were detected for all melting conditions, particularly for those not employing stirring. The EM stirring used in these experiments diminished the asymmetry of the pool and also caused a deeper pool. No compositional anomalies were detected. Mechanical testing suggests that the elevated Mg content of the PCHR material may improve the hot ductility of $u 718$.

This investigation indicates that the cold hearth melting of superalloys is technically feasible. Benefits would include the elimination of white spots related to VAR melt instabilities. However, the results also indicate that additional development work is needed to minimize asymmetrical tree-ring patterns and to prevent non-metallic inclusions from entering the mold.
\end{abstract}

Registered Trademark of Special Metals Corporation

Superalloys 1992

Edited by S.D. Antolovich, R.W. Stusrud, R.A. MacKay,

D.L. Anton, T. Khan, R.D. Kissinger, D.L. Klarstrom

The Minerals, Metals \& Materials Society, 1992 


\section{Introduction}

Cold hearth remelting (CHR) offers an alternative to the more common superalloy remelting processes such as vacuum arc remelting (VAR) and electroslag remelting (ESR). CHR is advantageous since it is possible to independently control melt rate, mold heating, and subsequently solidification pool profiles, suggesting that properly controlled CHR has the potential to produce ingots free from gross segregation and defects, such as white spots and oxide clusters.' Further, if plasma is the heat source, the process operates under a slightly positive inert gas pressure which precludes evaporation losses of beneficial elements such as $\mathrm{Cr}$ and $\mathrm{Mg}$ and deleterious elements such as $\mathrm{Bi}$ and $\mathrm{Pb}$. However, there is a concern that the force exerted by the torches on the melt surface creates turbulent conditions which could entrap non-metallic inclusions. It has also been suggested that inert gas may become dissolved during melting, causing material defects. A number of papers have been published on PCHR of Ti-base alloys ${ }^{2-5}$, the process ${ }^{6-8}$, and applicable control strategies ${ }^{9,10}$.

The solidification conditions present in a cold hearth withdrawal casting mold are believed to have two major shortcomings compared to static castings made in VAR processing. The first is the mechanical disruption of the solidification interface during the withdrawal motion; the second is the asymmetric entry of molten metal to the liquid pool. Both conditions are expected to produce macrosegregation banding which, if severe enough, cannot be adequately homogenized by thermal mechanical processes. Controlled molten metal mixing by either the plasma torch motion or electromagnetically induced stirring may be useful in reducing the severity of segregation and in refining solidification grain sizes. Experimental variables were chosen to evaluate the range of segregation that occurs when these variables are introduced.

\section{Experimental Procedure}

VIM melted $190 \mathrm{~mm}$ diameter electrodes were prepared by special Metals Corporation (SMC) and remelted in Retech's pilot scale PCHR furnace to $203 \mathrm{~mm}$ ingots. Prior to PCHR, the electrodes were cropped and samples for EBBT were secured. The electrodes were not surface conditioned before PCHR since it was desirable to evaluate the capability of PCHR to reduce non-metallic inclusions from dirty input material. Nominal composition of the U718 material is given in Table I.

Three PCHR heats and a $203 \mathrm{~mm}$ diameter VAR ingot were produced for metallurgical structure evaluation. Two of the three heats were utilized for a $2^{3-1}$ statistical experimental design evaluating three parameters: stirring, mold torch power, and "gas jet", by changing the conditions at the middle of each ingot. The principal melting parameters are summarized in Table II. The third ingot was melted using the parameters that gave the best surface and stable melt conditions; i.e., no stirring, low mold torch power, and use of the gas jet.

The PCHR furnace is schematically described in Figure 1. It is equipped with a water-cooled copper withdrawal mold and a cold hearth which holds $36 \mathrm{~kg}$ of nickel-based alloy. The electrode is fed from the side into the hearth and melted by a $250 \mathrm{~kW}$ hearth torch. During the experimental heats, this torch swung in a linear pattern across the face of the electrode with a cycle time of $47 \mathrm{sec}$. A $250 \mathrm{~kW}$ mold torch described a circular pattern close to the crucible wall and, every second time around, traveled over the pour lip. The cycle time for this torch, including two circles and one pour lip excursion, was $13 \mathrm{sec}$. Due to the configuration of this furnace, a physical or torchcreated slag barrier could not be employed. A gas jet blowing helium across the pour lip toward the hearth was employed for the bottom of PCHR 1 and top of PCHR 2 in an attempt to limit the amount of non-metallic slag entering the mold. All melting was conducted under a slight positive pressure of helium. The helium was recycled and gas contents of oxygen, hydrogen and water were continuously monitored during melting. The ingot was withdrawn using continuous positive withdrawal. All furnace parameters were automatically controlled using a Macintosh II-based torch profiling control system.

Table I. Nominal Composition of U718 Utilized (Weight $q$ ).

$\frac{\mathrm{C}}{0.025} \frac{\mathrm{Cr}}{18.0} \quad \frac{\mathrm{Ni}}{53.5} \quad \frac{\mathrm{Co}}{0.5} \quad \frac{\mathrm{Fe}}{18.0} \quad \frac{\mathrm{Mo}}{3.0} \quad \frac{\mathrm{Nb}}{5.35} \quad \frac{\mathrm{Ti}}{0.95} \frac{\mathrm{Al}}{0.5}$


Table II. Summary of Melting Parameters.

\begin{tabular}{|c|c|c|c|c|c|c|}
\hline Parameter & Ingc & PCHR 1 & Ingot & PCHR 2 & Ingot & Ingot \\
\hline & TOP & Bottom & TOP & Bottom & PCHR 3 & VAR \\
\hline stirring & OFF & OFF & ON & ON & OFF & $N / A$ \\
\hline Gas Jet & OFF & ON & ON & OFF & ON & $N / A$ \\
\hline Mold Torch power, $\mathrm{kW}$ & 125 & 175 & 120 & 170 & 125 & $N / A$ \\
\hline Melt Rate, $\mathrm{kg} / \mathrm{hr}$ & 143 & 143 & 132 & 132 & 132 & 133 \\
\hline
\end{tabular}

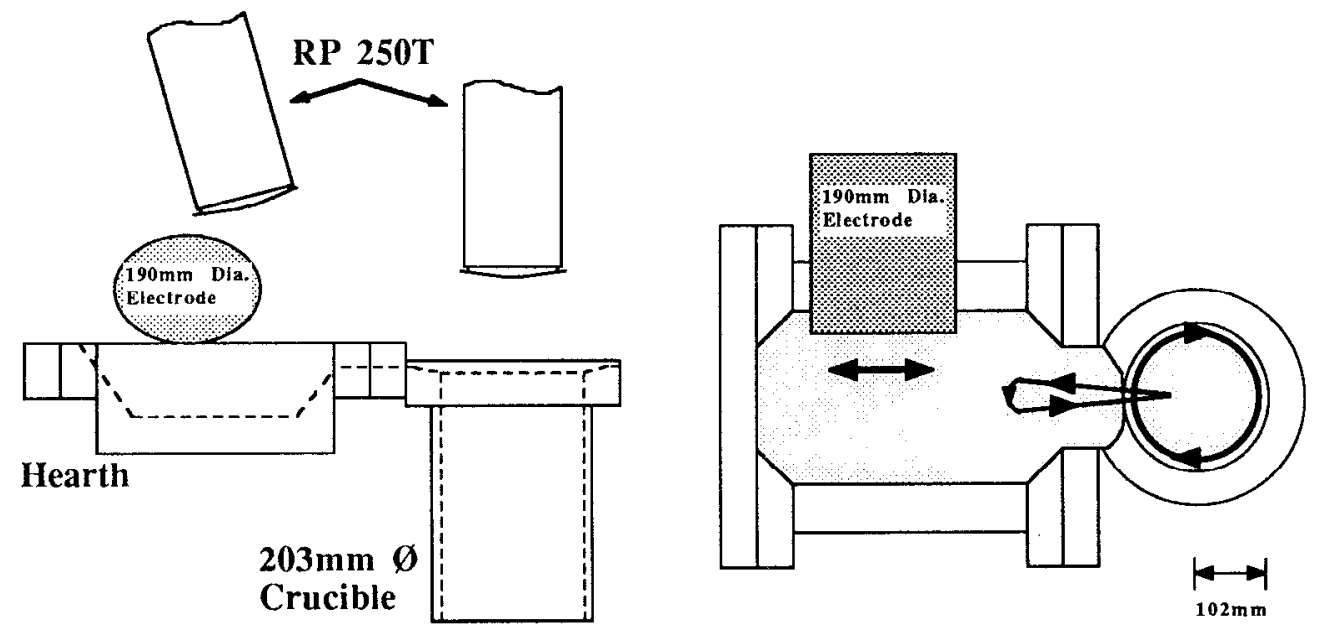

Figure 1. Schematic outline of PCHR furnace.

\section{Results and Discussion}

\section{Observations During Melting}

With few exceptions, the melting process was stable and proceeded at a steady rate once the transition zones were passed. The torches impacted the molten metal surface in a pattern visually resembling a gentle rain on water. A general depression on the metal surface was not observed at any of the power settings. While the hearth retained some of the non-metallics, the geometry of the furnace did not prevent non-metallics from entering the mold. However, it appeared that most of the inclusions that did enter the mold were pushed in front of the torches to become trapped on the edges of the ingot.

During the melting of PCHR 1, some difficulty controlling the melt rate was encountered. The operators had anticipated the melt rate to decrease at the midpoint reduction in mold torch power and adjusted the withdrawal rate accordingly. However, it became apparent that the melt rate was not strongly dependent on mold torch power, and the ingot had to be manually withdrawn. The withdrawal rate was then reset to the same as for the firgt half of the ingot.

During leak rate checking, before the melting of PCHR 2, a cracked view-port was detected and replaced. It is suspected that the view-port fractured early during melting of PCHR 1 causing increased nitrogen content in PCHR 1.

The combination of low torch power and Electro Magnetic stirring (EMS) in the mold during the latter part of PCHR 2 caused the torch to extinguish repeatedly.

\section{Evaluation of Material}

Surface Quality. An overall view of the ingots produced and corresponding hearths is shown in Figure 2 and close-up examples of ingot surface quality are shown in Figure 3. The bottom parts of all ingots were quite smooth. PCHR 1 had laps and seams associated with the uneven withdrawal motion previously discussed. The very top part of PCHR 1 had a smooth surface. This illustrates the need to ensure stable melt conditions and subsequently a stable, smooth 

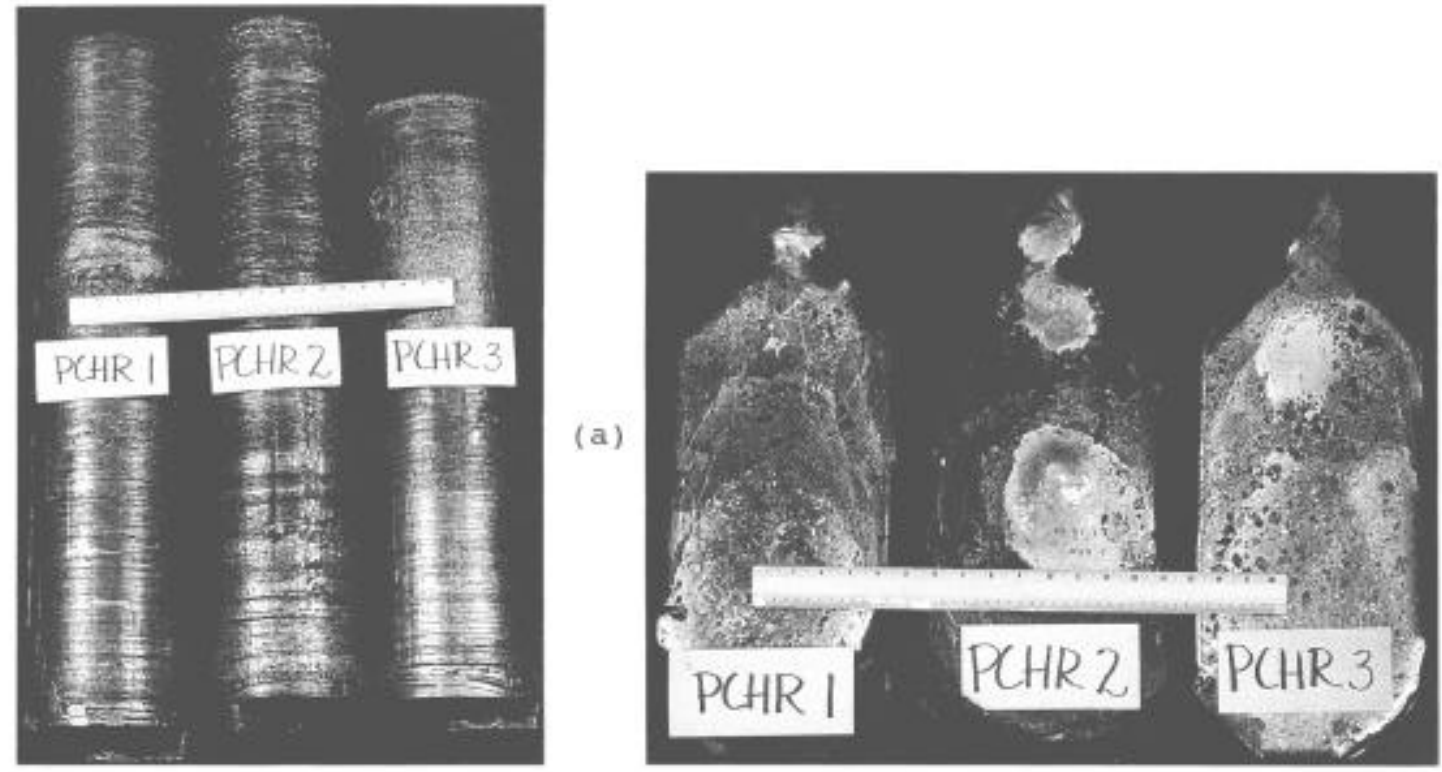

(b)

Figure 2. (a) Overall view of PCHR ingots and (b) corresponding hearths.

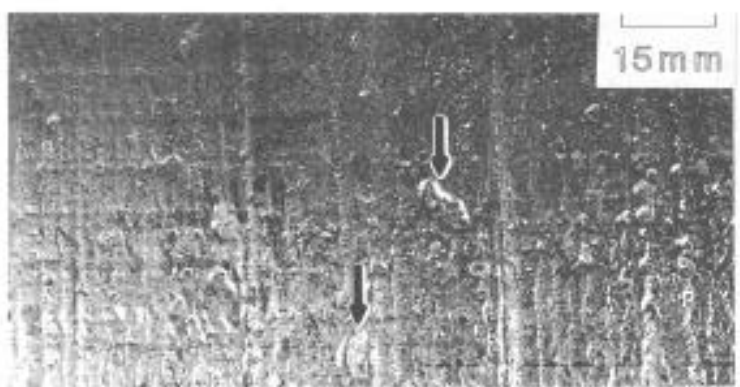

(a)

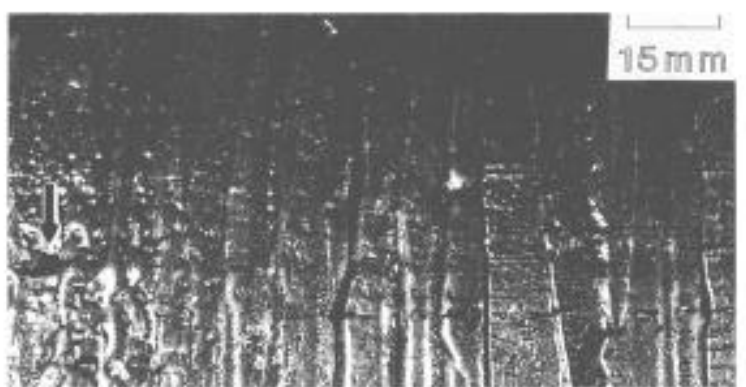

(b)

Figure 3. Examples of PCHR ingot surface quality. (a) PCHR 1 top and

(b) PCHR 2 top. Note non-metalilc inclusions by arrows.

withdrawal rate. The top of PCHR 2 had a rippled surface appearance that was due to the repeated extinguishing of the mold torch. All of the ingot surfaces show patches of non-metalic inclusions, indicating inclusions are removed from the bulk of the metal by being pushed to the mold wall. The surface by the pour lip tended to be smoother than the opposite side which could be due either to the greater input of heat adjacent to the mold by the metal flowing in from the hearth, or to the mold torch pattern.

Macro-structure. PCHR 1 and 2 were sectioned longitudinally and macroetched with Canada etch to show compositional variation, and with "grain size etch" ( 3 parts $\mathrm{H}_{2} \mathrm{O}, 2$ parts conc. $\mathrm{HCl}, 1$ part $\mathrm{H}_{2} \mathrm{O}_{2}(35$ wt 8)) to show the grain structure. Examples of the structures from the four melting conditions are shown in Figures 4 and 5, and corresponding structures from the comparison VAR ingot in Figure 6 .

Two features of the structures are immediately obvious: the pool tends to be asymmetrical, particularly for PCHR 1 where no stirring was employed; and there is a periodic tree-ring pattern. The asymmetrical pool profile may be explained by the input of molten metal to one side of the crucible or the asymmetrical mold torch sweep pattern, but is diminished by the use of EMS as seen from the structures of PCHR 2. The tree-ring pattern may be caused by the mold torch pattern (Figure 1) which circles twice around the perimeter and then diverts over the pour lip. At the time the torch diverts over the pour lip, a rush of metal also flows into the crucible. It appears that the finer tree-ring pattern observed by the edge of the ingot could be correlated to the 

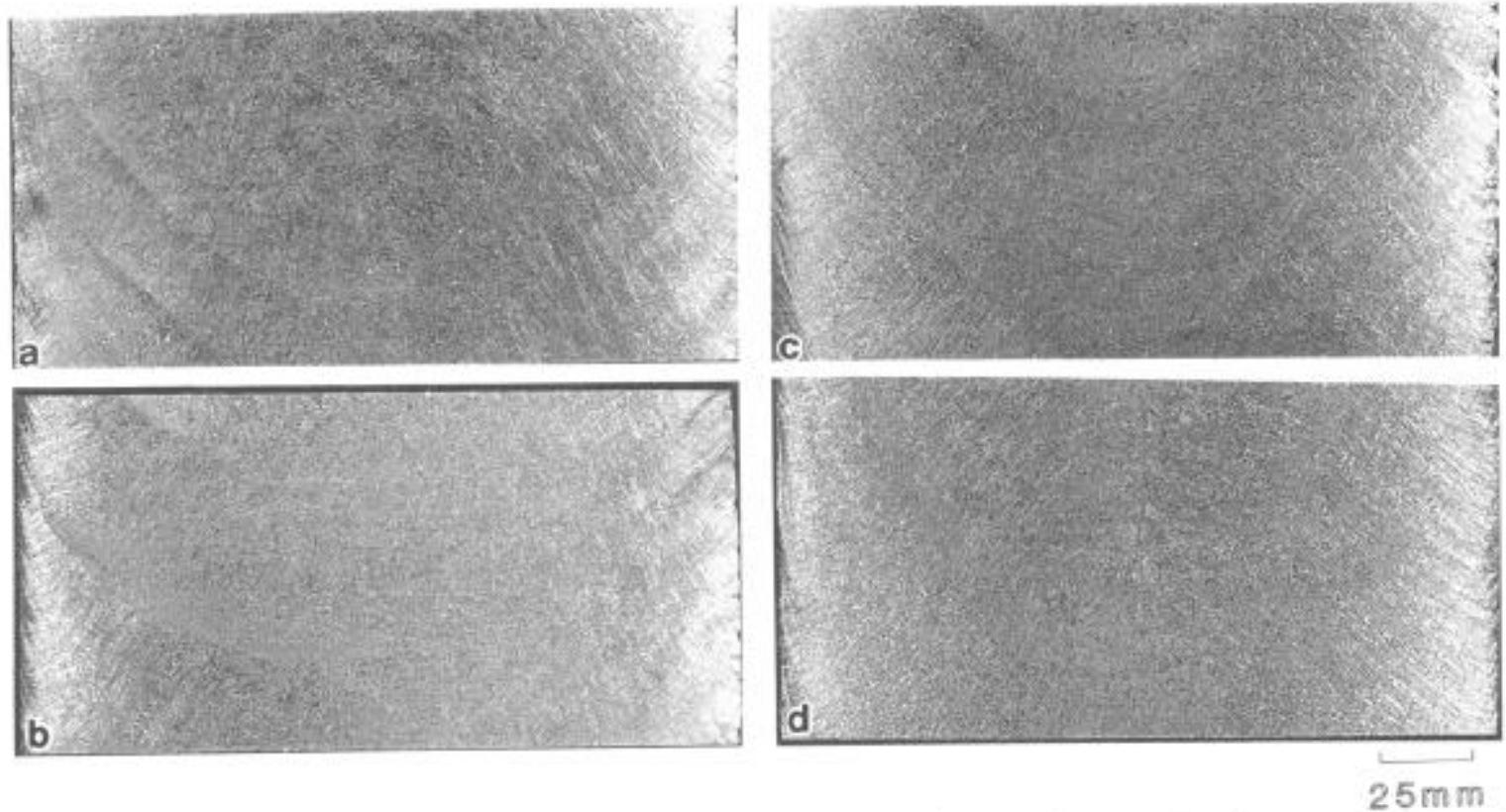

Figure 4. PCHR ingot macro-structures. Canada etch. PCHR 1 top (a) and bottom (b). PCHR 2 top (c) and bottom (d).
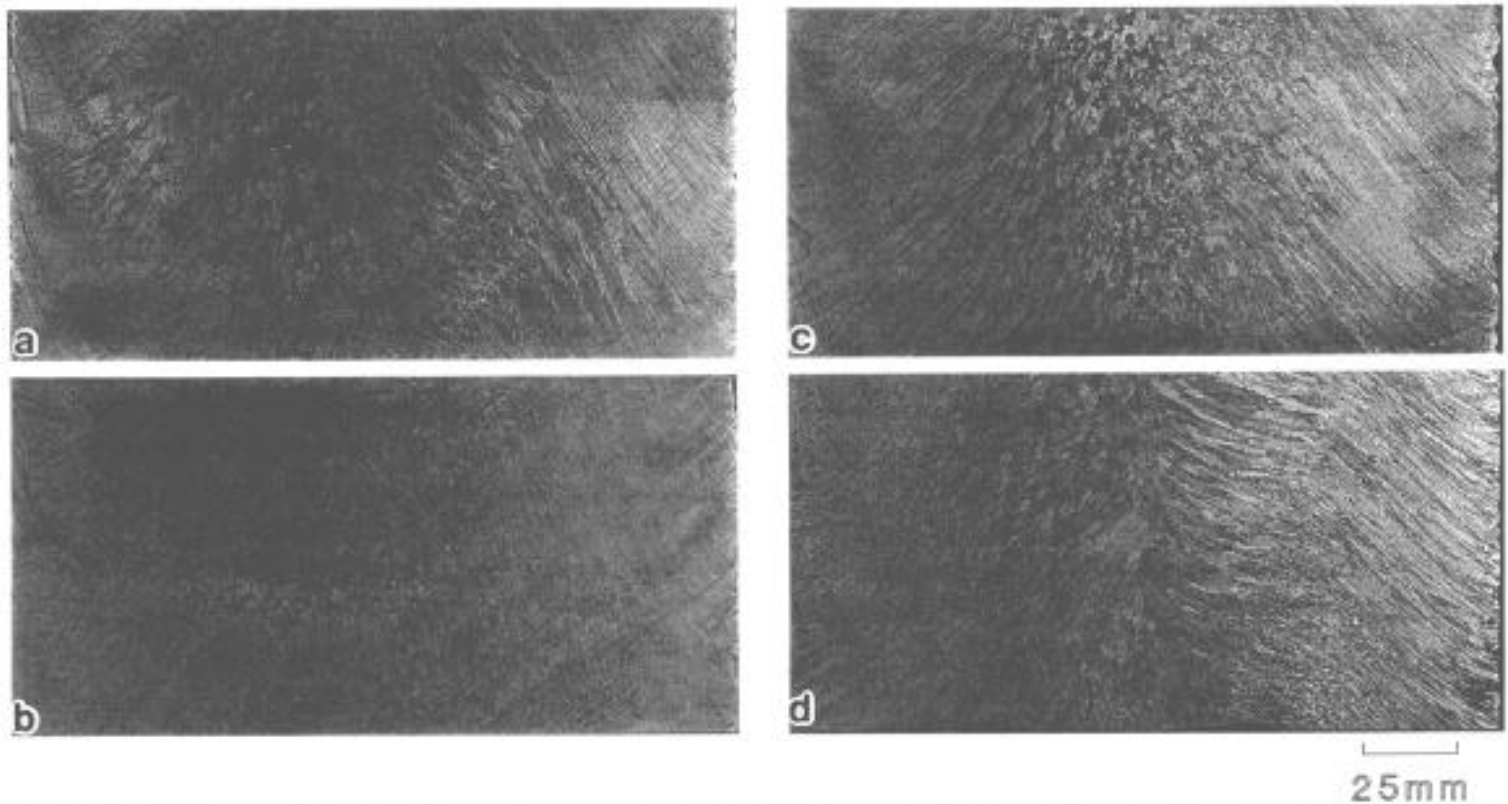

Figure 5. PCHR ingot macro-structures.

"Grain size" etch. PCHR 1 top (a) and bottom (b). PCHR 2 top (c) and bottom (d).

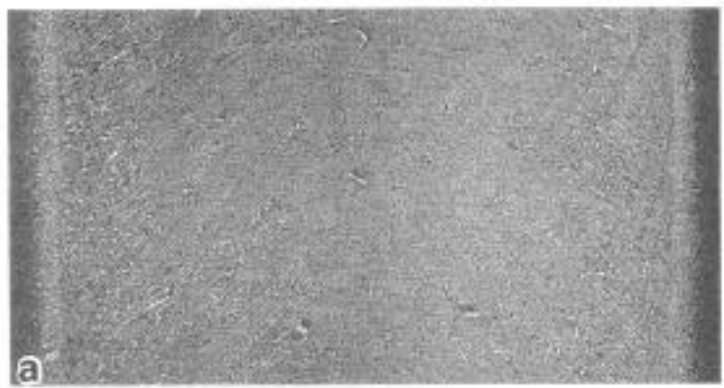

Figure 6. VAR ingot macro-structures. etch.

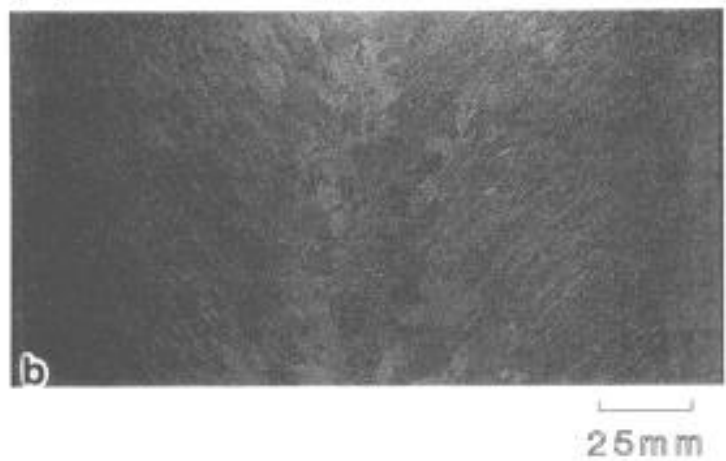

(a) Canada etch and (b) "Grain size" 
mold torch pattern. The coarser tree-ring pattern is not obviously correlated to any periodic processing event. The tree-ring pattern appears to be associated with a change in grain orientation, which is a clue to the heat transfer mechanism causing the tree rings. The molten pool profiles, including one for the comparison VAR ingot, are summarized in Figure 7 . The EM stirring causes a deeper, $v-$ shaped pool profile, possibly by

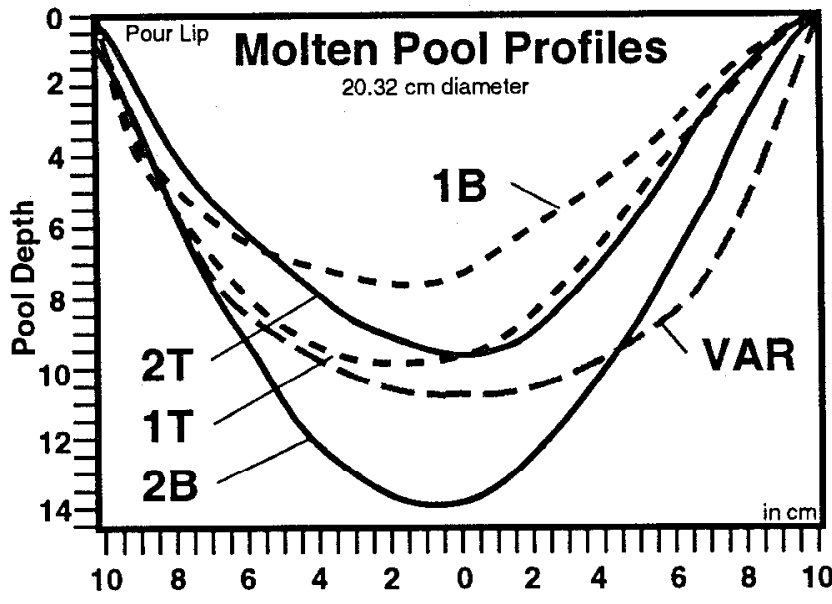

Figure 7. Molten pool profiles: 1T=PCHR 1 - top, 1B=PCHR 1 - bottom, 2T=PCHR 2 - top, $2 \mathrm{~B}=\mathrm{PCHR} 2$ - bottom, and VAR=VAR ingot. flattening out temperature gradients in the molten pool. In PCHR 1, the pool depth could be expected to decrease from the bottom (high power) to the top (low power). The results are the opposite, probably due to additional removal of heat by the gas jet during melting of the bottom part of the ingot. only the PCHR melt condition of high crucible torch power, stirring, and no gas jet creates a deeper pool than the VAR ingot pool. such a deep pool would be undesirable as it could cause formation of solute-rich defects; e.g., freckles. However, comparison of the macrostructures with the VAR ingot indicates that the grain structure remains finer in the PCHR ingots for all evaluated melting conditions.

Micro-structure. Metallographic samples were prepared by electrolytic etching $\left(208 \mathrm{H}_{2} \mathrm{SO}_{4}\right.$ in methanol, $\left.16 \mathrm{~V}\right)$ to reveal the dendrite arm spacing and the carbide structure. Typical examples of structures are shown in $F$ igure 8. Measurement of secondary dendrite arm spacings indicates that the local solidification time (LST) is approximately the same in the center of the VAR, the top of PCHR 1, and the bottom of PCHR 2, while the bottom of PCHR 1 and the top of PCHR 2 appear to have a shorter LST. As seen in Figure 9, the carbide size of the VAR melted material appears to be larger than the carbide size produced by all PCHR melting conditions. Since the carbon content of the VAR ingot was lower than that of the PCHR ingots, one would question the conclusion regarding LST drawn from the secondary dendrite arm spacing. An alternative explanation for the finer carbide size in the PCHR 1 ingot is that the higher Mg content of the PCHR material changes the carbide morphology as has previously been suggested by Xie"l.

Chemical Composition and Compositional Mapping. The chemical composition did not change noticeably from the electrode to the ingot during melting except for the elements reported in Table III. The content of magnesium was reduced, possibly through the physical removal of magnesium oxides, but remains at a higher level than that in vacuum melted materials. Although the oxygen content appears to have increased during PCHR melting of PCHR 2 , the change lies within the range of analytical error. PCHR 1 had a clear increase in nitrogen content which was suspected due to leakage through the cracked view-port. The nitrogen content remained constant from the electrode to the ingot in PCHR 2; consequently, the nitrogen pickup does not appear to be an inherent feature of the process. This incidence emphasizes the importance of ensuring the integrity of the PCHR furnace even though the process operates under a slightly positive pressure.

Chemical analysis was done on a series of samples from center to edge to determine if compositional gradients occurred. No gradients were detected for any of the analyzed elements in all four melting conditions.

Samples from the bottom of PCHR 1 and 2 were analyzed for helium content at Idaho National Engineering Laboratory using a fusion mass spectrometry method $^{12}$. As expected ${ }^{13}$, the helium contents of the samples were below the detectability limit; i. e., < 0.05 appm. 


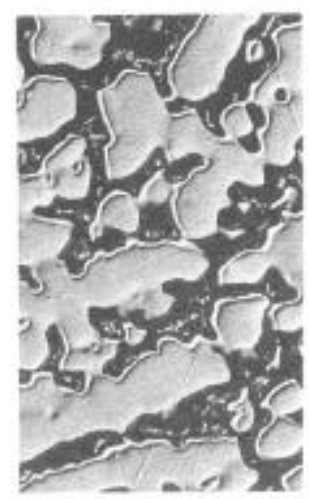

(a)

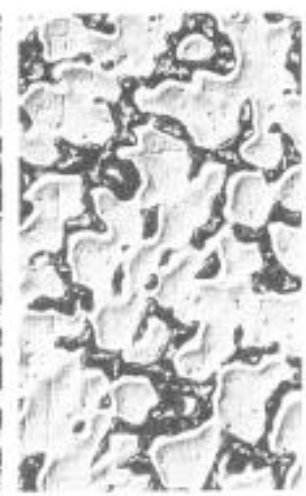

(b)

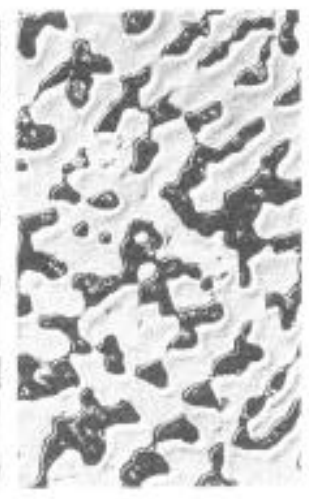

(c)

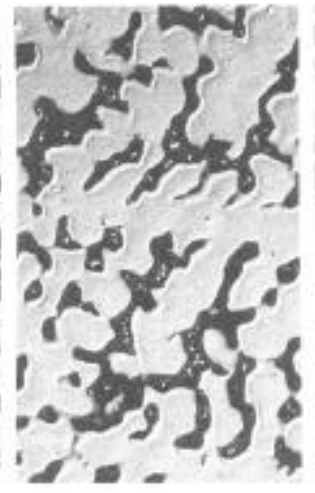

(d)

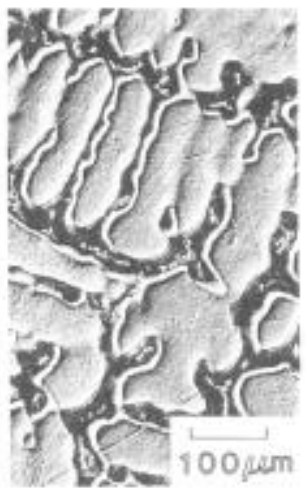

(e)

PCHR 2 top (c) and bottom (d). VAR ingot (e).

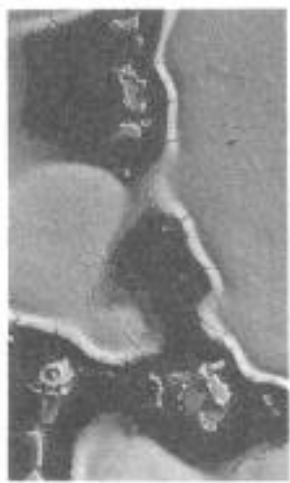

(a)

Eigure 9.0 (b)

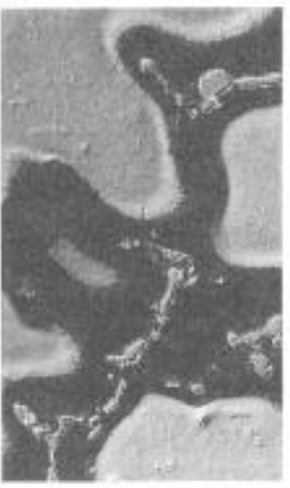

(b)

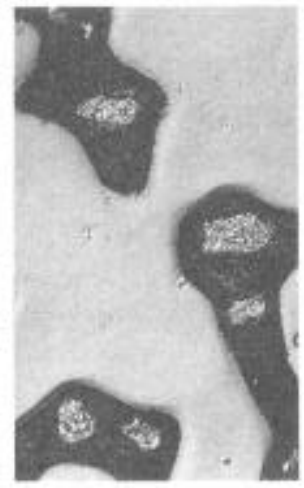

(c)

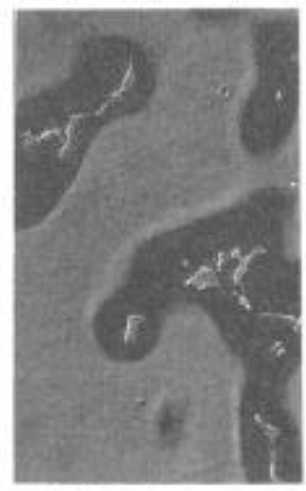

(d)

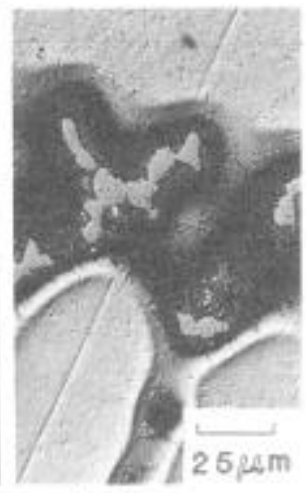

(e) PCHR 2 top (c) and bottom (d). VAR ingot (e).

The variation in $\mathrm{Nb}$ content in a longitudinal section was determined using a compositional mapping technique developed by Sandia Laboratories for the Specialty Metals Processing Consortium (SMPC) ${ }^{16}$. A slice from the bottom of PCHR 1 was selected because this melting condition appeared to result in the most macro-segregated structure. (See also Figures 4 and 5.) The mapping technique essentially consists of $x$-ray (Kevex) analysis in a grid pattern using a $6 \mathrm{~mm}$ diameter spot size. Thus, 510 points were analyzed on the $10 \times 20 \mathrm{~cm}$ silce.

Although the analysis was intended to determine variation in Nb concentration rather than absolute values, it was found to be in good agreement with the ingot heat analysis. The data in Figure 10 show a range of measured $\mathrm{Nb} c o n-$ centration between 5.12 to $5.58 \pm 0.04$ with an average value of 5.39 weight $\$$. This range of composition is relatively small if compared with the decrease in $\mathrm{Nb}$ content observed in "mini" ("solidification") white spots. "Mini" white spots typically have $\mathrm{Nb}$ contents of 3.9 to 4.9 weight $\mathrm{s}^{15}$. It is also notable that the lowest $\mathrm{Nb}$ contents were observed at the middle of the slice, where the formation of solute-rich defects, such as freckles, is more of a concern.

Table III. Results of Chemical Analysis. The only elements reported are those with a significant change in content during PCHR melting.

\begin{tabular}{cccc}
\hline Material & Mq $[\mathrm{ppm}]$ & $\mathrm{O}_{2}$ [ppm] & $N_{2}$ [ppm] \\
PCHR 1 - Electrode & 92 & 8 & 68 \\
Ingot - Top & 53 & 8 & 95 \\
Ingot - Bottom & 61 & 10 & 106 \\
PCHR 2 - Electrode & 74 & 3 & 75 \\
Ingot - Top & 53 & 8 & 73 \\
Ingot - Bottom & 57 & 9 & 78 \\
VAR Ingot & 17 & 4 & 65
\end{tabular}



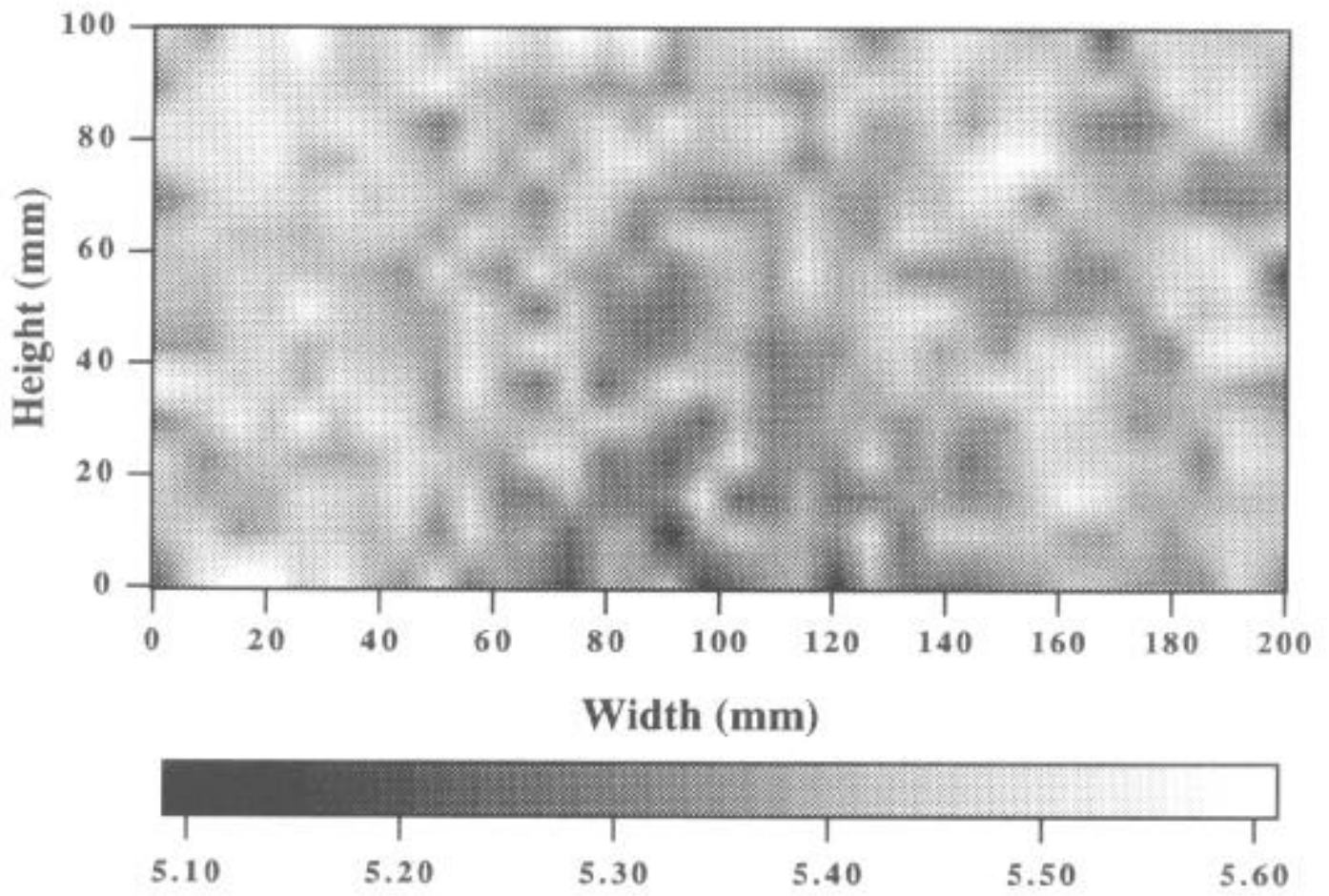

Nb Concentration $( \pm 0.04 \mathrm{wt} \%)$

Figure 10. Compositional map of $\mathrm{Nb}$ concentration in bottom part of PCHR 1.

Effect of $\mathrm{Mq}$ Content. To evaluate possible effects of the elevated magnesium content in the PCHR material, center samples from PCHR 1 and the comparison VAR material were hot worked $75 \%$ using a fine-grain rolling practice. The samples were subsequently heat treated for eight hours at $718^{\circ} \mathrm{C}$, furnace cooled $38^{\circ} \mathrm{C}$ per hour to $621^{\circ} \mathrm{C}$, and held at $621^{\circ} \mathrm{C}$ for eight hours. The resulting grain size was ASTM 8-10.

Mechanical test results are presented in Tables IV and V. All fall within the normal distribution for this material at SMC. As seen, the results are virtually identical for the two materials, except the PCHR material shows a higher hot ductility than the VAR material. To determine if this is due to the elevated magnesium content in the PCHR material requires additional evaluation.

Cleanliness. The electrodes, the PCHR ingots, and triple-melt (VIM-ESR-VAR) material were evaluated by Electron Beam Button cleanilness testing (EBBT). All EBBT tests were performed on polished samples cut from the center of the electrode/ingot. Thus, the unprepared electrode surface was not included in the electrode samples.

Table IV. Tensile Test Results of VAR and PCHR "Rolldown" Material.

\begin{tabular}{|c|c|c|c|c|c|}
\hline Sample & $\mathrm{T}\left[{ }^{\circ} \mathrm{C}\right]$ & UTS $[\mathrm{MPa}]$ & 0.2 YS [MPa] & EL $[q]$ & R.A. [F] \\
\hline VAR & RT & 1563 & 1466 & 17.6 & 48.7 \\
\hline PCHR I & RT & 1548 & 1444 & 17.1 & 49.2 \\
\hline VAR & 649 & 1285 & 1160 & 21.7 & 32.2 \\
\hline PCHR 1 & 649 & 1286 & 1162 & 29.0 & 65.5 \\
\hline
\end{tabular}

Table V. Summary of Stress Rupture Test Results at $649^{\circ} \mathrm{C}\left(1200^{\circ} \mathrm{F}\right)$ and $862 \mathrm{MPa}(125 \mathrm{ksi})$ Load.

\begin{tabular}{lcc}
\hline Sample & Life $[\mathrm{h}]$ & Elongation $[8]$ \\
VAR & 48.9 & 15.8 \\
PCHR 1 & 66.4 & 29.8 \\
\hline
\end{tabular}


As can be seen from the oxide cleanliness evaluation, Figure 11, there is approximately an order of magnitude improvement in cleanliness after PCHR melting. The resulting ingots have an oxide cleanliness rating comparable to triple melt material. previous work by shamblen et al. ${ }^{16}$ report similar improvements in superalloy cleanliness when VIM materials was electron beam cold hearth refined.

Quantitative nitride cleanliness ratings were not performed. However, on the EBBT samples from PCHR 1, a raft of nitrides was observed; no nitrides were observed on PCHR 2 EBBT samples. This is consistent with the higher nitrogen content in PCHR 1. In addition, regularly occurring clusters of nitrides were observed on polished as-cast samples of PCHR 1. This type of cluster was not observed on samples from PCHR 2 .

Barstock Evaluation. PCHR 3 was homogenized and then hot rolled from $203 \mathrm{~mm}$ diameter to $82 \mathrm{~mm}$ diameter using a fine-grain practice. Macroetch slices were prepared from top and bottom of the PCHR material and from a regular production $82 \mathrm{~mm}$ U718 bar. A very faint, asymmetrical tree-ring pattern could be observed in the slice corresponding to the top of the PCHR ingot. However, despite repeated attempts using various etches, including electrolytic etch, the tree-rings remained too faint to reproduce on a photograph.

\section{Summary Discussion}

The key to technical viability of cold hearth processing of superalloys is the capability to produce material that is at least as clean as triple melt, and that has an ingot macro- and microstructure at least as good as VAR or ESR processed material. This investigation evaluated PCHR melted $203 \mathrm{~mm}$ diameter U718 ingots. Application of PCHR commercial production of superalloys will require the capability to produce $508 \mathrm{~mm}$ diameter ingots as a minimum. The following conclusions are drawn as a result of this investigation:

- One order of magnitude improvement in EBBT oxide cleanliness was experienced through the PCHR melting process. The resulting cleanliness was comparable to triple melt U718. The removal of non-metallic inclusions can be expected to improve with appropriate furnace design.

- Asymmetrical trce-ring formation was detected in the ingots produced. To minimize tree-ring formation, an even, steady-state withdrawal speed is desirable. For larger ingot sizes, methods need to be developed to minimize the asymmetrical pool profile, for instance, torch pattern control, judicious use of electromagnetic stirring or ingot rotation.

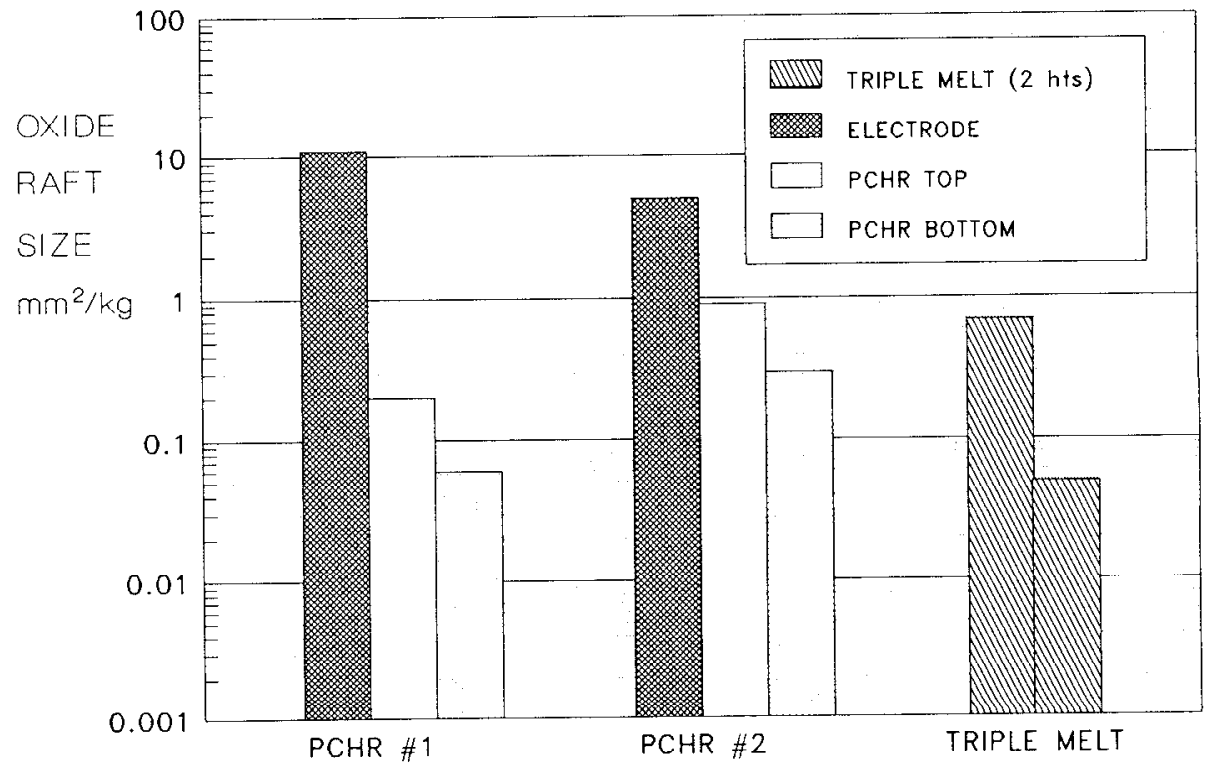

Figure 11. Results of Electron Beam Button Cleanliness testing. 


\section{Acknowledgements}

The support of the personnel of Retech and SMC in producing and evaluating the material, as well as in preparing the manuscript is gratefully acknowledged. We also thank John Flinn of Idaho National Laboartories for arranging the helium analysis, and Alec Mitchell for helpful discussions.

\section{References}

1. G. E. Maurer, "Primary and secondary Melt processing," Superalloys, Supercomposites and superceramics, eds: $f . K$. Tien and $W$. T. Caulfield, (Academic Press, 1989), 49-97.

2. R. C. Eschenbach and S. L. Stocks, "Plasma Melting of Large Diameter Titanium Ingots," (Paper presented at the AIME Annual Meeting, New Orleans, LA, 1986).

3. M. E. Schlienger, J. W. Sears, and R. C. Eschenbach, "Grain Size Effects in Plasma Cold-Hearth Withdrawal Melting," Symp Proc: Plasma Processing and synthesis of Materials III, MRS 1990, eds: D. Apelian, J. Szekely, 45-54.

4 W. R. Chinnis, R. C. Eschenbach, "Plasma Hearth Melting of Seeded $1988), 836-842$.

5. W. R. Chinnis, "Plasma Cold Hearth Melting of Titanium in a Production Furnace," Conference Proceedings: Titanium 1990, (USA: Titanium Development Association, 1990), 830-835.

6. R. Knight, R. W. Smith, and D. Apelian, "Application of Plasma Arc Melting Technology to Processing of Reactive Metals," International Metals Reviews, 36 (6) $1991,221-252$.

$7 . J . W$. Sears, "Current Processes for the Cold-Wall Melting of Titanium," JOM, March, 1990, 17-21.

8. H. Stumpp, G. Sick, H. Pannen, and W. Dietrich, "Advanced Melting and Casting Plants with the High Power Electron and Plasma Beam, "Vacuum, 41 (7-9) (1990), 2157-2160.

9. M. E. Schlienger and D. Malley, "Control Considerations in Cold Hearth Withdrawal," Electron Beam Melting and Refining - State of the Art 1989, ed: R. Bakish, $175-184$.

10. J. W. Sears and R. C. Eschenbach, "Optimization of Transferred-Arc Plasma Meiting Through Atmosphere and Torch Gas Control," ibid. 185-193.

11. X. Xie, F. Xu, B. Qu, G. Chen, J. F. Radavich, "The Role of Mg on Structure and Mechanical Properties ín Ailoy 718," Superalloys 1988, eds: D. N. Duhl, G. Maurer, S. Antolovich, C. Lund, S. Reichman, (warrendale', PA: The Metallurgical Society, 1988), 635-642.

12. G. R. Smolik and J. E. Delmore, "Analytical Method for Inert Gases in Alioy Powders," Material Science \& Engineering, A124 (1990), 15-19.

13. W. G. Wolfer, C. D. van Siclen, S. M. Foiles, and J. B. Adams, "Helium Solubility in Solid and Liquid Nickel," Acta Metallurgical, 37 (2) (1989), 579-585.

14. D. Wherry and B. Cross, "XRF, Microbeam Analysis, and Digital Imaging Combined into Powerful New Techniques," (Kevex corporation, Foster City, CA: Kevex Analyst, 1986) 12 (8) 8-9.

15. E. Samuelsson, J. A. Domingue, and G. E. Maurer, "Characterizing SoluteLean Defects in Superalloys," JOM, 42 (8) August, 1990, 27-30.

16. C. E. Shamblen, D. R. Chang, and J.A. Corrado, "Superalloy Melting and Cleanliness Evaluation," Superalloys 1984, ed: M. Gell et al.

(warrendale, PA: The Métal Iurgical Society, 1984), 509-519. 